\title{
FAMÍLIA E CLERO EM PORTUGAL
}

José Damiāo Rodrigues*

\section{Resumo}

A história social do clero, na intersecção da história social e da história religiosa, para não considerarmos senão duas vertentes de análise, não tem merecido por parte da historiografia portuguesa a mesma atenção que outros territórios de investigação. No presente texto, para além de uma visão geral relativamente a questões como as estratégias dos grupos familiares, os horizontes de promoção e as trajectórias sociais potenciais em matéria da carreira eclesiástica; o recrutamento e o papel das redes familiares e clientelares no acesso à carreira eclesiástica; a importância do património e a sua relação com a reprodução social; os comportamentos e a vida familiar dos membros do clero secular e regular, procuramos também apresentar perspectivas historiográficas que permitam definir novos programas de pesquisa e superar o actual nível de conhecimentos no tocante à identificação dos actores e dos respectivos grupos familiares, ao rastreio dos itinerários individuais e à construção de uma tipologia das carreiras eclesiásticas de clérigos, frades e freiras, que deverá inscrever os ciclos de vida, individuais e colectivos, nos contextos locais e regionais.

\section{História da família e história do clero em Portugal.}

Elaborar uma síntese relativa à interpenetração entre família e clero em Portugal nos séculos do Antigo Regime é uma tarefa que apresenta sérias dificuldades. Com efeito, embora os avanços historiográficos nos territórios da história social e da história da família sejam evidentes,

${ }^{*}$ Universidade dos Açores/CHAM.

Sociedade, Familia e Poder na Península Ibérica. Elementos para uma História Comparativa/Sociedad, Familia y Poder en la Península Ibérica. Elementos para una Historia Comparada, Lisboa, Ediçōes Colibri / CIDEHUS - Universidade de Evora / Universidad de Murcia, 2010, pp. 103-127. 
sobretudo quando consideramos a produção nacional das últimas duas décadas, muitas zonas permanecem ainda na penumbra. A história social do clero, na intersecção da história social e da história religiosa, para não considerarmos senão duas vertentes de análise, não tem merecido por parte da historiografia portuguesa a mesma atenção que outros territórios de investigação, razão pela qual os textos mais recentes que focaram a sua atenção nesse domínio são unânimes na declaração do muito que há ainda por fazer ${ }^{1}$. Apontemos alguns dos problemas com que ainda se defronta, neste momento, a construção de uma síntese.

Se os grupos nobiliárquicos e as nobrezas locais se têm destacado como objectos de análise preferencial por parte dos historiadores, nem todos os estudos, porém, consideraram, no seu inquérito, a questão das estratégias familiares e das carreiras eclesiásticas; de igual modo, carecemos de mais investigaçóes que nos revelem, de forma segura, qual a relação entre as elites locais e os cabidos e as colegiadas, em termos de redes de parentesco e de clientelismo, modalidades de recrutamento e estratégias de consolidação e reprodução social, à imagem de contribuições recentes da historiografia espanhola ${ }^{2}$. Face ao universo da nobreza, desconhecemos ainda muito da dinâmica entre os demais estratos sociais e o clero, regular e secular, não sendo possível, por ora, ultrapassarmos as afirmaçôes de teor generalista, alicerçadas em dados respigados aqui e ali em análises parcelares. Por fim, em relação às casas monásticas, sublinhemos que, de um modo geral, o seu papel enquanto senhorios tem prevalecido, remetendo para segundo plano investigaçóes sistemáticas sobre ordens e casas que tivessem como fio condutor a caracterização

1 Cf. Mafalda Soares da CUNHA, A Casa de Bragança 1560-1640. Práticas senhoriais e redes clientelares, Lisboa, 2000, p. 332; Fernanda ENES, "Clero Secular. II. Séculos XVI-XVIII (de Trento a Pombal)" in Carlos Moreira AZEVEDO (dir.), Dicionário de História Religiosa de Portugal, vol. 1, Lisboa, 2000, pp. 361-370, maxime p. 369; Maria de Lurdes Correia FERNANDES, "Da reforma da Igreja à reforma dos cristãos: reformas, pastoral e espiritualidade" in Carlos Moreira AZEVEDO (dir.), História Religiosa de Portugal. Humanismos e Reformas, vol. 2, Lisboa, 2000, pp. 15-47; José Pedro PAIVA, "Os mentores" in Carlos Moreira AZEVEDO (dir.), História Religiosa de Portugal. Humanismos e reformas, vol.2, pp. 201-237; José Pedro PAIVA, "The Portuguese Secular Clergy in the Sixteenth and Seventeenth Centuries" in Eszter ANDOR e István György TÓTH (eds.), Frontiers of Faith. Religious Exchange and the Constitution of Religious Identities, 1400-1750, Budapeste, 2001, pp. 157-166.

2 Entre outros exemplos, María Luisa CANDAU CHACÓN, La Carrera Eclesiástica en el Siglo XVIII. Modelos, cauces y formas de promoción en la Sevilla rural, Sevilha, 1993; Francisco José ARANDA PÉREZ (coord.), Sociedad y élites eclesiásticas en la España moderna, Cuenca, 2000; Antonio IRIGOYEN LÓPEZ, Entre el cielo y la tierra, entre la familia y la institución: el Cabildo de la Catedral de Murcia en el siglo XVII, Murcia, 2001. 
sociológica dos membros de um dado convento ou mosteiro, a sua identificação - mais do que a respectiva origem social, interessaria conhecer as famílias e os lugares de nascimento - e a integração em redes de parentesco, que permitissem perceber, para além das limitaçóes das próprias fontes, como funcionavam efectivamente essas redes, nomeadamente na selecção de novos membros e no momento de eleiçôes. Com a eventual excepção da ilha de São $\mathrm{Miguel}^{3}$, poucas serão as regióes do país para as quais dispomos de uma imagem relativamente clara do quadro humano das instituiçóes eclesiásticas no período moderno. Perante as lacunas expostas - outras mais existem, que não enunciamos aqui -, as ideias que apresentamos de seguida não pretendem constituir mais do que meras interrogaçōes e releituras das articulaçōes existentes entre família e clero, estruturadas em torno de quatro eixos de reflexão, interligados entre si, que constituem outros tantos hipotéticos tópicos de pesquisa.

\section{Família e clero: linhas gerais.}

\subsection{A carreira eclesiástica: estratégias dos grupos familiares, hori- zontes de promoção, itinerários.}

Começando pela questão do número, as avaliações mais recentes ${ }^{4}$, não obstante as falhas de informação, apontam para o crescimento do corpo clerical ao longo do Antigo Regime, quer por parte do clero regular, quer do secular. As cifras que surgem nos "Mappas de Portugal, ou Padrão do número das Freguesias, moradores, e almas etca", de 1765, elaborados por Manuel José Perinlongue, a mando do conde de Oeiras, corrigidas por Maria Luís Rocha Pinto e João Pedro Ferro, sugerem que o total de efectivos das ordens religiosas existentes no reino de Portugal em meados do século XVIII se situaria entre os 10 e os 15.000 indivíduos, estando, no

\footnotetext{
3 Maria Margarida de Sá Nogueira LALANDA, $A$ admissão aos mosteiros de Clarissas na ilha de S. Miguel (sécs. XVI e XVII), dissertação de provas de A. P. C. C., Ponta Delgada, Universidade dos Açores, 1987, policopiado; Maria Margarida de Sá Nogueira LALANDA, "Do convento de Jesus, na Ribeira Grande (S. Miguel), no século XVII: as cartas de dote de uma freira”, Arquipélago-história, 2a série, vol. I, In memoriam Maria Olimpia da Rocha Gil, 2: Estudos Insulares, pp. 111-125; José Damião RODRIGUES, São Miguel no século XVIII: casa, elites e poder, vol. I, Ponta Delgada, 2003 [2004], Susana Goulart COSTA, Viver e morrer religiosamente. Ilha de São Miguel, século XVIII, Ponta Delgada, 2007.

${ }^{4}$ Fernando Taveira da FONSECA, "Demografia eclesiástica. II. Do século XVI aos inícios do século XX” in Carlos Moreira AZEVEDO (dir.), Dicionário de História Religiosa de Portugal, vol. 2, Lisboa, 2000, pp. 47-59; José Pedro PAIVA, "Os mentores”, opus cit.; José Pedro PAIVA, “The Portuguese Secular Clergy...”, opus cit.
} 
início do século XIX, um pouco abaixo dos 17.000 indivíduos 5 . Sublinhemos que todos estes números dizem respeito a cômputos globais num momento específico, não permitindo inferir da evolução populacional de uma dada ordem ou casa. A este respeito, só com uma investigação sistemática será possível definir os ritmos de adesão às diferentes ordens ao longo dos séculos XVII e XVIII ${ }^{6}$. Com efeito, enquanto alguns conventos parecem ter conhecido uma estabilidade populacional durante este período, outros, pelo contrário, sofreram oscilações marcadas nos seus efectivos. Quanto aos seculares, a sua quantificação à escala nacional revela-se, de momento, empreendimento inexequível ${ }^{7}$.

Se os dados conhecidos indiciam, em termos globais, um crescimento do corpo eclesiástico, é preciso não esquecer que o primeiro estado era caracterizado por uma grande heterogeneidade, sendo de relevar, neste plano, a existência de assimetrias regionais e de uma demografia diferencial, em termos geográficos e sociais, com reflexos directos no ratio de clérigos e de religiosos por fogos/número de habitantes 8 e, consequentemente, na distribuição das rendas e na actuação e influência dos membros da Igreja sobre as populaçôes. Uma das consequências visíveis do aumento da população eclesiástica foi o aparecimento de um "clero desempregado", falando mesmo alguns autores na existência de "uma verdadeira legiāo de clérigos vagabundos" ", que importaria quantificar com exactidão, identificando-se em simultâneo as raízes geográficas, familiares e sociais e os motivos que explicavam a sua mobilidade. Neste particular, embora não pretendamos minimizar o impacto dos espaços e modos de vida urbanos no contexto das sociedades tradicionais do Antigo Regime, tanto mais que a maioria dos estabelecimentos monásticos e dos elementos do clero secular se concentrava nos núcleos urbanos, a oposição entre clero rural e clero urbano, comum em certas análises, parece revelar-se uma dicotomia pouco operatória. Em primeiro lugar, a

5 João Pedro FERro, A População Portuguesa no Final do Antigo Regime (1750-1815), Lisboa, 1995; José Damião RODRIGUES, “A Estrutura Social” in Avelino de Freitas de MENESES (coord.), Portugal, da Paz da Restauração ao Ouro do Brasil, A. H. de Oliveira MARQUES, Joel SERRĀO (dir.), Nova História de Portugal, vol. VII, Lisboa, 2001, pp. 404-441, maxime 420-421.

6 Como exemplo, consultem-se os mapas relativos ao ingresso de monges na Congregação de São Bernardo para a primeira metade do século XVIII: cf. Biblioteca Nacional, Lisboa (BNL), Fundo Geral, cod. 1482.

7 José Pedro PAIVA, “Os mentores”, opus cit.; José Pedro PAIVA, “The Portuguese Secular Clergy...”, opus cit.

8 Maria Fernanda ENES, "Uma carta de D. Filipe I sobre o clero das ilhas dos Açores de 1590", Arquipélago, Série Ciências Sociais Humanas, no especial, 1983, pp. 61-95; Fernando Taveira da FONSECA “Demografia Eclesiástica...”, opus cit.

9 Maria Fernanda ENES, “Clero Secular...”, opus cit., p. 363. 
grande maioria do clero diocesano e, consequentemente, de todo o corpo secular, era composta pelos sacerdotes que tinham a seu cargo os pequenos centros urbanos e as paróquias rurais, auferindo rendimentos mais baixos e com um modo de vida que, por vezes, pouco se diferenciaria do dos estratos populares, no contexto de uma sociedade vincadamente rural. Depois, existia alguma mobilidade, não compatível com classificações rígidas. $\mathrm{Na}$ ausência de monografias e estudos comparativos, está por apurar a real dimensão deste fenómeno, não sendo possível, neste momento, afirmar se os padres migrantes eram uma figura típica da épo$\mathrm{ca}$, conforme registou Timothy Tackett para a França do século XVIII ${ }^{10}$.

De um modo geral, o clero secular parecia caracterizar-se por uma "estabilidade paroquial" 11 . O recrutamento dos seus efectivos assentava em bases locais e regionais e, ao nível dos priores, dados publicados apontam para a sua longa permanência numa mesma paróquia. No entanto, em algumas regiōes, como o Algarve, os curas mudavam frequentemente de freguesia ${ }^{12}$ e, no topo da hierarquia paroquial, existia uma maior mobilidade, assinalada para diferentes espaços do território nacional ${ }^{13}$. Note-se que era possível aos titulares de um priorado ou benefício permutarem de lugar, por troca com outros titulares, caso tal conviesse aos interessados, ou concorrerem para benefícios vagos ${ }^{14}$. Esta mobilidade eclesiástica prendia-se, em parte, com a procura de lugares mais rendosos e de promoção social, afinal um dos atractivos, juntamente com os privilégios, do estado eclesiástico. A carreira eclesiástica oferecia, à partida, diversas oportunidades profissionais, nem sempre relacionadas com as funçōes religiosas, mas, na prática, verificava-se que, em termos das trajectórias sociais potenciais, existiam diferenças evidentes, sendo possível detectarmos uma relação entre a origem social do indivíduo e o grau e a função que desempenhava ou a que podia aspirar ${ }^{15}$.

10 Timothy TACKETT, "L'histoire sociale du clergé diocésain dans la France du XVIII siècle”, Révue d'Histoire Moderne et Contemporaine, t. XXVII, 1979, pp. 198-234, maxime pp. 200-201.

11 José Pedro PAIVA, “Os mentores”, opus cit., p. 223.

12 Joaquim Romero MAGALHĀES, O Algarve Económico (1600-1773), Lisboa, 1988, pp. 352-353.

13 José Pedro PAIVA, “Os mentores”, opus cit., p. 223; José Damião RODRIGUES, São Miguel no século XVIII..., opus cit., vol. I, pp. 532-538; Fernando de SOUSA, "O clero da diocese do Porto em tempo das Cortes Constituintes", Revista de História, vol. II, Actas do Colóquio "O Porto na Época Moderna”, 1979, pp. 245-263, maxime p. 247.

14 Ana Mouta FARIA, "Função da carreira eclesiástica na organização do tecido social do Antigo Regime", Ler História, no 11, 1987, pp. 29-46, maxime p. 32.

15 Ana Mouta FARIA, "Função da carreira eclesiástica...", opus cit.; José Pedro PAIVA, "Os mentores", opus cit. 
$\mathrm{Na}$ cúspide da hierarquia da Igreja em Portugal, o provimento episcopal era, desde o reinado de D. Manuel I, uma competência do monar$\mathrm{ca}$, sendo de sublinhar quer a existência de relaçóes de tipo clientelar entre a maior parte dos providos e o rei que os nomeara, quer o facto de, sobretudo no caso das dioceses do reino, a nomeação para uma mitra ser considerada uma mercê. Neste contexto, não é de estranhar que os arcebispos de Braga, Lisboa e Évora e os bispos das principais dioceses fossem geralmente filhos legítimos ou bastardos dos próprios monarcas e de titulares que gravitavam em torno do centro político e que melhor podiam aproveitar a lógica de uma "economia da graça". O protagonismo de importantes casas nobiliárquicas ao nível das prelaturas está patente na presença assídua de indivíduos das linhagens dos Vimioso, dos Bragança, dos Lencastre ou dos Távora ocupando cadeiras episcopais ${ }^{16}$. Entre os reitores da Universidade de Coimbra, embora o espectro social fosse mais amplo, entre o final de Quinhentos e os inícios de Oitocentos também figuram um Nuno da Silva Teles, filho do primeiro marquês de Alegrete, e o sobrinho, homónimo, filho do segundo marquês de Alegrete; um D. Nuno Álvares Pereira de Melo, filho bastardo do primeiro duque de Cadaval, que foi também Inquisidor e bispo de Lamego; ou um D. Diogo de Castro do Rio Furtado de Mendonça, filho do conde, visconde e senhor de Barbacena ${ }^{17}$.

Ao nível dos abades e priores e nos cabidos das sés, detectamos também a presença de nobres: as dignidades de arcediago, arcipreste e vigário da vara, por exemplo, exigiam um menor grau clerical, mas maiores habilitações universitárias - logo, possibilitavam aos titulares auferirem um vencimento superior -, o que não estava nas possibilidades da maior parte das famílias pertencentes ao terceiro estado. Segundo Joaquim Romero Magalhães, no Algarve dos séculos XVII e XVIII, os quadros médios da Igreja (cónegos, beneficiados) sairiam do grupo das famílias nobres da governança, os notáveis locais ${ }^{18}$. Do mesmo modo, no Porto quinhentista ${ }^{19}$, na Braga setecentista ${ }^{20}$ ou nos Açores ${ }^{21}$, as oligarquias clericais (cónegos da Sé,

16 José Pedro PAIVA, Os Bispos de Portugal e do Império 1495-1777, Coimbra, 2006, pp. 243-251.

17 Manuel Augusto RODRIGUES, A Universidade de Coimbra e os seus Reitores: para uma história da instituição, Coimbra, 1990.

18 Joaquim Romero MAGALHĀES, O Algarve..., opus cit., p. 343.

19 Pedro de BRITO, Patriciado urbano quinhentista: as famílias dominantes do Porto (1500-1580), Porto, 1997.

20 Ana Maria da Costa MACEDO, Família, Sociedade e Estratégias de Poder (1750-1830): A Família de Jácome de Vasconcelos da Freguesia de S. Tiago da CividadeBraga, Braga, 1996.

21 António dos Santos PEREIRA, A Ilha de S. Jorge (Séculos XV-XVII). Contribuição 
nos casos do Porto e de Braga; ouvidores eclesiásticos; vigários e abades de paróquias; membros das colegiadas) eram formadas, na sua maioria, por indivíduos das famílias dominantes à escala local. Nos escalóes mais baixos do clero secular, pior remunerados e menos exigentes do ponto de vista da formação intelectual, encontraríamos, então, aqueles cuja origem social estava nos grupos das famílias secundárias das vereaçóes, dos pequenos proprietários e rendeiros e dos artesãos, gente que, em princípio, podia dispor de bens de raiz que assegurassem a constituição de um património. $\mathrm{Na}$ comarca trasmontana, em finais do Antigo Regime, a carreira sacerdotal surgia não tanto como uma "fuga à miséria", mas mais como um investimento familiar no prestígio social: a "Gente rustica" buscava ordenar os filhos "com o fim de honrarem as Famílias."22.

Também no universo conventual eram perceptíveis estas demarcações, quer em termos de ordens, quer, inclusivamente, de casas de uma mesma regra: as ordens monásticas recebiam a preferência da fidalguia e da nobreza, enquanto as ordens mendicantes (Franciscanos, Dominicanos, Carmelitas), sediadas sobretudo nos meios urbanos, acolhiam maioritariamente elementos do estado popular e as novas congregaçōes, de origem quinhentista e seiscentista, apresentavam entre os seus membros um leque social mais diversificado. Segundo Ana Mouta Faria, nos séculos XVII e XVIII a grande nobreza parece ter demonstrado uma relação preferencial pelos Dominicanos e Gracianos; já os filhos e filhas de escalóes mais baixos da nobreza eram canalizados para a religião seráfica ou para os Jerónimos, onde se podiam encontrar igualmente filhos de mercadores ${ }^{23}$. Cândido dos Santos confirmou, para esta última ordem, que a base de recrutamento se encontrava predominantemente entre as famílias da pequena nobreza, do oficialato local e central e da gente dos mesteres ${ }^{24}$. No caso do Oratório, estudado por Eugénio dos Santos, embora encontremos, nas diferentes casas, congregados saídos da nobreza, filhos de letrados e de mercadores, os seus membros eram, na maior parte, originários de famílias de pequenos proprietários rurais e urbanos e de artífices ${ }^{25}$.

para o seu estudo, Ponta Delgada, 1987; José Damião RODRIGUES, São Miguel no século XVIII..., opus cit., vol. I.

22 Fernando de SOUSA, "Subsídios para a História Social do Arcebispado de Braga - A Comarca de Vila Real nos fins do Século XVIII", Bracara Augusta, vol. XXX (II), no 70, 1976, pp. 399-586, maxime p. 411.

23 Ana Mouta FARIA, "Função da carreira eclesiástica...", opus cit., pp. 39-40 e 44-45.

${ }^{24}$ Cândido dos SANTOS, Os Jerónimos em Portugal - Das origens aos fins do século XVII, Porto, 1980.

25 Eugénio dos SANTOS, O Oratório no Norte de Portugal. Contribuição para o estudo da história religiosa e social, Porto, 1982. 
A propósito das estratégias familiares e do ingresso das jovens nos mosteiros, façamos um parêntese para lembrar que a dinâmica dos jogos de alianças e o acaso biológico impediam, por vezes, que a vida de clausura decidida para algumas mulheres fosse concretizada. As condicionantes da política matrimonial das famílias estão bem patentes numa passagem de frei Diogo das Chagas, cronista açoriano, natural das Flores. A necessidade das famílias adoptarem estratégias reprodutivas que jogassem com o equilíbrio entre o número e o sexo dos filhos, por um lado, e o património, por outro, transparece na situação das filhas do capitão Rafael Cardoso de Novais, da governança de Ponta Delgada (foi vereador em 1637 e 1642)26. Delas escreveu o cronista que "ambas estam em casa de seus Pays, moças de pouca idade de boas partes e musicas excellentes pera freiras mas como os pays não tem outros filhos, nem esperança de os ter, por conseruar a caza as querem cazar." $27 \mathrm{Ou}$ seja, o destino inicial das moças, o claustro, foi alterado, em função de um objectivo mais importante, a reprodução da casa, face à ausência de varões.

$\mathrm{O}$ quadro muito geral acima delineado não deve impedir-nos de ver que a análise das situações concretas das casas e das famílias se revestia de uma maior complexidade. Por exemplo, a casa ducal de Bragança, no que respeita ao patrocinato das ordens, apoiou os reformados capuchos e outros ramos da Religião Seráfica. As filhas dos duques foram colocadas no mosteiro das Chagas, em Vila Viçosa, onde também professaram jovens oriundas das famílias nobres dependentes dos Bragança: cerca de $65 \%$ das filhas solteiras da elite clientelar brigantina ingressaram nos conventos de Vila Viçosa ${ }^{28}$. Esta protecção à Ordem Franciscana, com a entrada das jovens para os mosteiros de Clarissas, também se encontrava ao nível da coroa e de outras poderosas casas nobres, como a de Aveiro ${ }^{29}$, mas os Bragança apoiaram igualmente Agostinhos e Jesuítas. Relativamente aos Agostinhos, entre o início do último quartel de Quatrocentos e a reforma da ordem, em meados dos anos de 1530, o convento de Vila Viçosa, protegido pelos duques, viveu uma época áurea, num "regime quase autónomo" 30 .

26 José Damião RODRIGUES, Poder Municipal e Oligarquias Urbanas: Ponta Delgada no Século XVII, Ponta Delgada, 1994, pp. 163 e 402.

27 Diogo das CHAGAS (Frei), Espelho Cristalino em Jardim de Várias Flores, Angra do Heroísmo-Ponta Delgada, 1989, p. 209.

28 Mafalda Soares da CUNHA, A Casa de Bragança..., opus cit., pp. 360-369 e 489.

${ }^{29}$ Maria de Lurdes Correia FERNANDES, "Da reforma da Igreja...", opus cit., pp. 17-18.

30 Carlos ALONSO, "Agostinhos" in Carlos Moreira AZEVEDO (dir.), Dicionário de História Religiosa de Portugal, vol. 1, Lisboa, 2000, pp. 27-32, maxime p. 28. 
As ordens religiosas eram pólos de poder e, por este motivo, as diferentes famílias ou facçōes dos vários escalóes da nobreza procuravam associar-se ou dominar os mais importantes focos de irradiação desse poder. Assim, podemos constatar que, no Porto, três das famílias que estão presentes no senado da cidade no século XVI (Madureiras, Camelos e Baiôes) terão ficado a dever a origem da sua promoção e afirmação sociais ao elo que garantiram com os Cónegos Regrantes de Santo Agostinho $^{31}$. Por outro lado, importa reter que as redes familiares e de sociabilidade exteriores às paredes conventuais se prolongavam pelo seu interior, originando disputas em torno do controlo das posiçōes de relevo ${ }^{32}$.

Todos estes elementos são importantes para a elaboração de uma geografia social do corpo eclesiástico, mas necessitamos de ir mais além no conhecimento da articulação entre família e clero. Sabemos que o recurso ao celibato definitivo, o masculino e o feminino, era uma estratégia bem implantada entre as famílias dos diversos escalóes da nobreza, conquanto existissem situaçôes e políticas distintas ${ }^{33}$, e os níveis superiores do terceiro estado. Nos mosteiros, era frequente serem colocadas irmãs e primas, tias e sobrinhas, o que possibilitava a constituição de "verdadeiras oligarquias"34. Porém, sem a realização de novos estudos, agora com o recurso a perspectivas microanalíticas e ao cruzamento nominativo de fontes, como saberemos quantos consanguíneos ou parentes por afinidade residiram dentro das paredes de um mesmo convento num dado momento ou ao longo do tempo? E, sem uma análise sistemática das múltiplas histórias familiares e das genealogias disponíveis, as impressas - vejam-se, por exemplo, os esclarecedores elementos publicados para $\mathrm{Braga}^{35}$ - ou as manuscritas inventariadas, não poderemos pretender conhecer a evolução dos modelos reprodutivos e das estratégias familiares no que respeita à canalização, geração a geração e ramo a ramo, da descendência legítima e ilegítima das famílias para a carreira eclesiástica.

Conhecemos bem o modelo organizativo diocesano ${ }^{36}$, tal como os nomes dos prelados, o respectivo meio social e familiar de origem, a sua

31 Pedro de BRITO, Patriciado urbano quinhentista..., opus cit., pp. 106 e 293-294.

32 José Damião RODRIGUES, “A Estrutura Social”, opus cit., p. 420; José Damião RODRIGUES, São Miguel no século XVIII..., opus cit., vol. I, pp. 474-475.

33 Mafalda Soares da CUNHA, A Casa de Bragança..., opus cit., pp. 480-491.

34 José Pedro PAIVA, “Os mentores”, opus cit., p. 206.

35 Domingos de Araújo AFONSO, "Da verdadeira origem de algumas famílias ilustres de Braga e seu termo", Bracara Augusta, vol. XX, no 43-44, 1966, pp. 78-116; vol. XX, no 45-46, 1966, pp. 283-306; vol. XXIII, no 55, 1969, pp. 132-147; vol. XXIII, no 56, 1969, pp. 129-145; vol. XXIV, no 57-58, 1970, pp. 123-137.

36 José Pedro PAIVA, “Dioceses e organização...”, opus cit. 
relação com a coroa e, em alguns casos, as dominantes das trajectórias de vida e, graças aos estudos de José Pedro Paiva, é já possível possível ter uma primeira e sólida visão de conjunto do episcopado português no período moderno ${ }^{37}$; no entanto, não possuímos estudos à semelhança do que Hermínia Vasconcelos Vilar ${ }^{38}$ efectuou para a diocese de Évora no período medieval, delineando percursos de formação e ascensão e explorando redes relacionais. E, se dispomos de informações pertinentes relativamente a cabidos e colegiadas, a indisponibilidade de prosopografias relativas ao quadro humano que integrava a hierarquia das dioceses, cortes episcopais e corpos capitulares, condiciona o desenho de um esboço global destes universos.

Finalmente, pouco ou nada sabemos quanto ao número e origem geográfica, social e familiar desse desconhecido clero paroquial que preenchia a maioria das vigararias e curatos, às modalidades de carreira e ritmos de recrutamento, às condiçôes materiais de existência, às diferenças regionais, contrariamente ao que sucede em Espanha, que dispóe de estudos modelares e sugestivos neste domínio ${ }^{39}$. Os horizontes de promoção e os itinerários possíveis dependiam não apenas da raiz social e familiar dos actores, mas igualmente da sua posição individual no contexto familiar e comunitário e das redes de parentesco e respectiva influência, conforme mostrou Fernanda Olival no tocante ao Santo Ofício ${ }^{40}$. Se entre o "deão de uma grande sé, oriundo de distinta família fidalga" e um "singelo presbítero", "um humilde rapaz que ficara órfāo" ${ }^{11}$, o fosso social era profundamente cavado e as oportunidades não eram as mesmas, os itinerários individuais modais estão, todavia, por conhecer. É uma questão, entre outras, que reclama a atenção historiográfica.

37 José Pedro PAIVA, Os Bispos..., opus cit.

38 Hermínia Vasconcelos VILAR, As Dimensões de um Poder - A Diocese de Évora na Idade Média, Lisboa, 1999.

39 Embora com uma perspectiva diferente da que aqui expomos, vejam-se as referências para o período moderno contidas em Enrique GARCÍA HERNÁN, "Visión acerca del estado actual en España de la historia de la Iglesia", Anuario de Historia de la Iglesia, vol. XVI, 2007, pp. 281-308.

40 Fernanda OLIVAL, "Clero e família: os notários e comissários do Santo Ofício no Sul de Portugal (o caso de Beja na primeira metade do século XVIII)", Nuevo Mundo Mundos Nuevos [En línea], Coloquios, 2008, colocado on line a 23 de Março de 2008. URL: http://nuevomundo.revues.org/index28712.html.

41 José Pedro PAIVA, “Os mentores”, opus cit., p. 212. 


\subsection{O acesso à carreira eclesiástica: recrutamento, redes familiares e clientelares.}

Conforme se depreende da leitura do ponto anterior, o acesso à carreira eclesiástica estava condicionado por algumas barreiras, entre as quais o grupo social a que pertencia a família do indivíduo. No contexto de uma sociedade em que a mundivisão dominante era a de um todo social organizado em estados, onde o peso do estatuto jurídico era central na definição do lugar social de cada um, esta não era uma questão menor ${ }^{42}$. E, embora a capilaridade social fosse um fenómeno observável no Portugal do Antigo Regime, não se encontrava generalizada, nem seria fácil, sobretudo no mundo rural. Daí a importância dos laços familiares e clientelares no quadro de uma estratégia de promoção que passasse pela carreira eclesiástica, secular ou regular. Conforme Maria Olímpia da Rocha Gil: "Era frequente, entre os grupos mais influentes, ter-se um irmão cónego, uma tia ou duas primas freiras, um filho frade, um cunhado padre, etc., o que só beneficiava, no conjunto, a família em questão que via alargar-se deste modo a sua esfera de conhecimentos, a sua área de acção e interferência." 43

No que respeita ao provimento de dioceses, como demonstrou José Pedro Paiva, se a última palavra cabia ao monarca, por ocasião da nomeação de um bispo confluíam na escolha final cinco pólos de decisão, que aquele autor identificou e hierarquizou: o rei; um círculo restrito de actores orbitando à volta do trono (a rainha, um confessor régio, um ministro, etc.); um número indeterminado de mediadores entre os candidatos a bispo e os demais pólos de decisão; altas figuras da monarquia, com participação no exercício do poder (vice-reis, governadores do reino, membros do Conselho de Estado, Secretários de Estado, entre outros); e, por fim, os próprios candidatos à mitra, espaldados pela respectiva família e amigos próximos $^{44}$. $\mathrm{Na}$ ausência de normativas e de uma regulação dos procedimentos, com excepção para uma maior formalização durante o período da União Ibérica, era deste complexo emaranhado de redes pessoais e de interesses que resultava a nomeação de um novo prelado ${ }^{45}$. Na longa duração, é de relevar a existência de relaçóes clientelares entre a maior parte dos providos e o rei que efectuava a escolha. De igual modo, se bem que os dados conhecidos revelem que a família não era "o nervo central na escolha de um bispo", a influência dos laços de parentesco não deixou de se fazer sen-

42 José Damião RODRIGUES, “A Estrutura Social”, opus cit., pp. 405-412.

43 Maria Olímpia da Rocha GIL, O Arquipélago dos Açores no Século XVII. Aspectos sócio-económicos (1575-1675), Castelo Branco, 1979, p. 159.

44 José Pedro PAIVA, Os Bispos..., opus. cit., pp. 251-253.

45 José Pedro PAIVA, Os Bispos..., opus. cit., pp. 213-277. 
tir e é mesmo possível identificar linhagens bem sucedidas, constituindo quase "dinastias episcopais", como exemplificam os Lencastre ${ }^{46}$.

Em termos do clero secular, a maioria dos lugares eram providos sem que fossem realizados concursos; nesses casos, pesava a nomeação de quem detinha o direito de apresentação ou padroado ${ }^{47}$. Na diocese de Coimbra, em 350 paróquias, 215 tinham um padroeiro eclesiástico, 133 um secular e em duas a apresentação era feita alternadamente. Os párocos eram quem detinha o maior número de padroados, 73 (20,92\%), seguindo-se, entre os principais padroeiros, os conventos, com 52 (14,90\%), o rei, com 50 $(14,33 \%)$, os senhores seculares - a saber, os duques de Cadaval e de Lafōes (que incorporou direitos de padroado pertencentes à casa de Aveiro, após a extinção desta), o conde de Pombeiro e o senhor de Melo -, com 44 $(12,61 \%)$, o cabido, com $38(10,89 \%)$ e, abaixo deste, o bispo, com 32 $(8,88 \%)^{48}$. No caso das Ordens de Cristo, Avis e Santiago, incorporadas perpetuamente na coroa portuguesa com D. João III, após 1551 o provimento dos benefícios eclesiásticos dos Mestrados passou a depender da Mesa da Consciência e Ordens, conforme determinou o regimento de 1558 daquele tribunal régio. No entanto, o monarca, enquanto "governador e perpétuo administrador da ordem e cavalaria do Mestrado de Nosso Senhor Jesus Cristo", não abdicou de interferir no processo. Conhecemos o processo e a tramitação dos concursos e provimentos para o caso da Ordem de Avis no Alentejo, em finais do século XVII ${ }^{49}$ e para os Açores (São Miguel) no século XVIII, onde, desde 1568, as dignidades e os benefícios da diocese deviam ser providos por "oposição", isto é, por meio de um exame, como preconizavam os ditames do Concílio de Trento ${ }^{50}$. Porém, quer num, quer noutro caso, as excepções existiam.

O panorama dos concursos não era uniforme: perante lugares muito

46 José Pedro PAIVA, Os Bispos..., opus. cit., pp. 243-251.

47 Fernanda OLIVAL, Nuno Gonçalo MONTEIRO, "Mobilidade social nas carreiras eclesiásticas em Portugal”, Análise Social, vol. XXXVII, nº 165, Inverno 2003, pp. 1213-1239, maxime pp. 1227-1228.

48 Joaquim Ramos de CARVAlHO, José Pedro PAIVA, “A diocese de Coimbra no século XVIII. População, oragos, padroados e títulos dos párocos”, Revista de História das Ideias, no 11, Cultura, Política, Mentalidades, 1989, pp. 175-268.

49 Fernanda OLIVAL, "Os concursos destinados às capelanias da Ordem de Avis a Sul do Tejo (1680-1689)" in $2^{\circ}$ Encontro de História Regional e Local do Distrito de Portalegre. Actas, Portalegre-Nisa, 1996, pp. 232-239; Fernanda OLIVAL, "O clero da Ordem de Avis na região alentejana (1680-1689): concursos e provimentos" in Ordens Militares: guerra, religião, poder e cultura - Actas do III Encontro sobre Ordens Militares, vol. II, Lisboa, 1999, pp. 187-221.

50 José Damião RODRIGUES, São Miguel no século XVIII..., opus cit., vol. I, pp. 499-503; Susana Goulart COSTA, Viver e morrer..., opus cit., pp. 111-112 e $150-165$. 
pretendidos e até fortemente disputados, como as vigararias das cidades e vilas mais importantes, outros surgiam sem candidatos, porque pouco rentáveis e menos prestigiantes. Era ao nível do provimento ou colação em benefícios apetecíveis, pela renda e/ou pela honra, quando os interesses de indivíduos, famílias e facçôes concorriam entre si no tabuleiro do jogo político e social, que se activavam as redes familiares e clientelares, visando assegurar o sucesso do investimento, e certos concursos não escapavam à polémica ${ }^{51}$. Os dados estudados para a Ordem de Avis sugerem que, entre os candidatos (eclesiásticos da própria Ordem, conventuais e clérigos de São Pedro), não haveria ninguém acima dos escalóes da nobreza local e que, no processo de selecção, além da nobreza, eram valorizadas a formação académica e a antiguidade na Ordem. A garantia de êxito, contudo, residia em deter uma carta de favor do rei ${ }^{52}$. O papel da coroa não se confinava à passagem de cartas de favor a candidatos que pretendiam obter provimento em benefícios de uma Ordem. No caso das dioceses, em especial nos períodos de sede vacante, a intervenção régia fazia-se igualmente sentir no tocante ao ingresso de novos membros no estado eclesiástico, quer condicionando o acesso de jovens às ordens sacras, quer protegendo este ou aquele candidato, que integrava as clientelas régias ${ }^{53}$.

Mas, no quadro das estruturas de poder diocesanas, em períodos de normalidade política e institucional, eram as relaçōes privadas com os titulares das mitras e a integração nas redes clientelares dos bispos que se afirmavam como requisitos essenciais para que tal indivíduo ingressasse no estado eclesiástico ou, sendo clérigo, fosse provido num lugar vago. $\mathrm{Na}$ diocese do Porto, entre 1745 e 1826, num total de 48 benefícios e canonicatos da Sé, quinze foram providos em parentes (irmãos, sobrinhos) dos que já ocupavam tais posiçōes; nove foram-no em "familiares" dos bispos; e três em elementos do aparelho administrativo episcopal ${ }^{54}$. Sublinhemos a ligação pessoal ao prelado como elemento de peso no provimento de um benefício, tanto mais que conhecemos o percurso de "familiares" de bispos que desempenharam funçōes de relevo em mais de uma diocese, mas sempre ao serviço do mesmo prelado. As relações pessoais mantidas com os titulares de dioceses eram prestigiantes e configuravam-se como condição essencial no dealbar de uma carreira que se pretendia de sucesso. Assim terão pensado os patriarcas da família Jácome de

51 Fernanda OLIVAL, "Os concursos destinados às capelanias...”, opus cit.

52 Fernanda OLIVAL, "O clero da ordem de Avis...”, opus cit.

53 José Pedro PAIVA, "As relações entre o Estado e a Igreja após a Restauração. A correspondência de D. João IV para o cabido da Sé de Évora”, Revista de História das Ideias, no 22, O Estado e a Igreja. Homenagem a José Antunes, 2001, pp. 107-131.

54 Fernando de SOUSA, "O clero da diocese do Porto...”, opus cit. 
Vasconcelos, de Braga. A família, uma das mais influentes da cidade, detinha um relacionamento privilegiado com o arcebispo e um reflexo dessa convivência íntima foi o facto das cerimónias das ordens de prima tonsura dos netos de João Luís Jácome de Sousa (1735-1810) terem sido efectuadas em casa deste, em 1807, presidindo à celebração o próprio arcebispo ${ }^{55}$.

A ligação de dada família a uma poderosa casa nobiliárquica e a sua integração na rede clientelar desta cumpriam os mesmos objectivos. Dentro do círculo de dependentes da casa ducal de Bragança, a família Lucena ilustra, por mais de uma geração, como o serviço e a fidelidade a um senhor, no quadro de uma economia distributiva, garantiam o destino clerical dos filhos ${ }^{56}$. No oposto da hierarquia social, ao nível das freguesias rurais, as redes clientelares, cruzadas ou sobrepostas ao círculo da parentela, também se manifestavam e o episódio dado a conhecer por José Pedro Paiva ${ }^{57}$ para Avô sugere isso mesmo: em 1678, por ocasião de uma visita, um padre foi acusado de viver amancebado e ter um filho, mas respondeu em público que "enquanto houvesse Magalhães e Mexias e Curados que se lhe não dava das culpas que se lhe fulminassem". As situaçôes-limite seriam as de nepotismo, que, todavia, foram raras. $\mathrm{O}$ caso mais notório foi o de Jorge da Costa, o célebre cardeal Alpedrinha, que, na viragem do século XV para o XVI, obteve a nomeação de dois irmãos para as dioceses de Braga e Lisboa e dos sobrinhos para o Porto, onde um sucedeu ao outro.

Comentando agora a situação dos conventos e mosteiros, diremos que o panorama não diferia do que se passava com os clérigos, embora estejamos melhor informados acerca da realidade dos mosteiros femininos do que sobre os processos de recrutamento e progressão dentro do universo regular masculino. Por um lado, os titulares do padroado das casas procuravam controlar o processo de admissão e impunham regras, que deveriam ser obedecidas; por outro, as redes internas, de parentesco ou clientelismo, eram accionadas em momentos chave, como o exame de uma nova candidata ou uma eleição. Ao lado da crença e da devoção a um santo por parte dos fundadores de uma casa monástica, existia uma preocupação com a reprodução social da sua família, aspecto que está bem patente nos documentos de dote e fundação dos mosteiros femininos, nos quais foram registadas as condiçôes do padroado e cláusulas que

55 Ana Maria da Costa MACEDO, Família, Sociedade..., opus cit., p. 177.

56 Mafalda Soares da CUNHA, A Casa de Bragança..., opus cit., pp. 350-352.

57 José Pedro PAIVA, “A administração diocesana e a presença da Igreja. O caso da diocese de Coimbra nos séculos XVII e XVIII", Lusitania Sacra, 2a série, vol. III, Portugal e a Reforma Católica - Catolicismo e Liberalismo, 1991, pp.71-110, maxime p. 98. 
o regulavam. Para além das propriedades e rendas com que os conventos eram dotados, necessárias à sua conservação, os padroeiros procuravam garantir certas vantagens para os seus sucessores ou herdeiros. Nesse sentido, fixavam o número de parentes, nomeavam as linhas que podiam entrar no convento e, eventualmente, estabeleciam outras condições. Para os padroeiros de um mosteiro, este constituiria o destino "natural" das filhas que não participariam das transacções matrimoniais. Em relação às famílias que pretendiam fazer ingressar na vida monástica as filhas marginalizadas do jogo de alianças, as famílias patronais apresentavam a vantagem de usufruírem de um número fixo de lugares reservado para esse fim. Esta situação colocava, pelo menos no início, as parentes dos patronos em posição privilegiada para os jogos de influências no interior dos mosteiros. Não esqueçamos que a entrada para um estabelecimento feminino requeria uma patente do custódio provincial e estava sujeita à votação da comunidade.

Representando a carreira eclesiástica uma objectivação das estratégias familiares, existia uma estreita relação entre as religiosas e o meio familiar e social de origem e a documentação monacal confirma a forte presença dos laços familiares no interior dos universos claustrais. Em Ponta Delgada, uma patente de frei António da Madalena, custódio provincial dos Franciscanos na custódia de São Miguel e Santa Maria, de 9 de Novembro de 1769 e dirigida à abadessa e religiosas do mosteiro de Santo André, criticava o luto excessivo que algumas freiras dedicavam aos parentes falecidos, parecendo que os apreciavam mais do que a Deus, o que era pecaminoso e detestável, "porque com a mortte daqueles se privam por muitos mezes dos actos da comunidade". Ordenou, por isso, que, passados alguns dias, as religiosas retomassem a vida comum; as que resistissem seriam impedidas de ir à grade, às portas e às rodas ${ }^{58}$.

Além dos conventos, também os recolhimentos, que Antonio Domínguez Ortiz"59 definiu como "manifestaciones espontáneas de vida regular", reproduziam este modelo. Desempenhando uma função igualmente importante no que se referia ao destino das mulheres, estes institutos recebiam uma parte dos elementos femininos que pretendiam abandonar o século. Em Cuba ${ }^{60}$, no Baixo Alentejo; na "Évora Gloriosa"

58 Biblioteca Pública e Arquivo Regional de Ponta Delgada, Monásticos, Convento de Santo André, Vila Franca do Campo, 191, Registo de patentes de prelados, sem no fl. Os primeiros nove fls. apresentam assentos de religiosas (1731-1785).

59 Antonio DOMÍNGUEZ ORTIZ, Las clases privilegiadas en el Antiguo Régimen, $3^{a}$ ed., Madrid, 1985, p. 322.

60 Emília Salvado BORGES, Homens, Fazenda e Poder no Alentejo de Setecentos: o caso de Cuba, Lisboa, 2000, pp. 129, 131-132 e 147-148. 
descrita em começos do século XVIII pelo padre Francisco da Fonseca ${ }^{61}$; em Braga ${ }^{62}$; ou nos Açores ${ }^{63}$, deparamos com elementos das principais famílias das elites locais na origem destas instituiçōes, onde se refugiaram mulheres, novas e velhas, que, por motivos diversos (orfandade, maus tratos, viuvez, pobreza, devoção), dificilmente conseguiriam assegurar a sobrevivência sem o apoio destas casas. Noutros casos, porém, as jovens eram colocadas nos recolhimentos à guarda de parentas, enquanto os pais não asseguravam os meios necessários para lhes proporcionar estado adequado à sua qualidade. Para estas mulheres, a vida nos recolhimentos seria assim apenas uma etapa transitória no seu ciclo de vida; para outras, uma solução definitiva.

\subsection{Património e reprodução social.}

$\mathrm{O}$ ingresso na carreira sacerdotal não implicava que todos os candidatos alcançassem o sacramento da Ordem. $\mathrm{Na}$ passagem das ordens menores para as maiores, muitos dos pretendentes não conseguiam obter um rendimento mínimo que lhes garantisse a imprescindível independência financeira. $\mathrm{O}$ vínculo financeiro podia tomar várias feições: património, benefício eclesiástico, tença ou outro título que garantisse a sobrevivência do ordenando, à margem da malha administrativa diocesana. Além do mais, em termos de cursus honorum, a exigência de estudos superiores e de um grau académico para o exercício de uma vigararia, por exemplo, eram factores condicionantes nas aspirações dos que percorriam uma carreira eclesiástica. Apenas os grupos possidentes dispunham dos bens necessários a um tal investimento. Deste modo, a base social de recrutamento dos vigários seria forçosamente distinta da dos curas, ainda que houvesse sobreposições pontuais. Reconhecendo os insuficientes conhecimentos que possuímos quanto a esta questão, avancemos, todavia, com alguns exemplos reveladores.

$\mathrm{Na}$ diocese do Porto, apenas cinco fidalgos da Casa Real foram pro-

61 Francisco da FONSECA (Padre), Evora Gloriosa Epilogo dos quatro Tomos da Evora Illustrada, que compoz o R. P. M. Manoel Fialho da Companhia de Jesu. [...], Roma, na Officina Komarakiana, 1728, pp. 231-236.

62 Maria Ivone da Paz SOARES, Sociabilidade Feminina: Enquadramento religioso no quotidiano da sociedade bracarense setecentista, dissertação de mestrado, Braga, Instituto de Ciências Sociais da Universidade do Minho, 1997, policopiado.

63 Artur Teodoro de MATOS, "Vivências, comportamentos e percursos das recolhidas de Santa Bárbara de Ponta Delgada nos séculos XVII a XX: contributos para uma monografia" in Actas do Colóquio Comemorativo dos 450 anos da Cidade de Ponta Delgada, Ponta Delgada, 1999, pp. 141-152; José Damião RODRIGUES, São Miguel no século XVIII..., opus cit., vol. I, pp. 477 e 480-481. 
vidos em benefícios e canonicatos da Sé nos anos de 1745 a 1826 e, no mesmo período, abraçaram a carreira sacerdotal 34 filhos de Dona, 27 filhos de lavradores, nove descendentes de mercadores e cinco de bacharéis e doutores. No entanto, apesar das diferenças de estatuto social e das assimetrias de riqueza dos ascendentes, os ordenandos provinham de famílias que possuíam bens de raiz e podiam, assim, constituir património, cujo rendimento líquido anual estava acima dos 40.000 réis $^{64}$. Em Cuba, os processos de ordenandos atestam, de igual modo, que os futuros sacerdotes eram oriundos de famílias de grandes e médios proprietários locais ou dos arredores, entre os quais pontuavam lavradores abastados que viviam à lei da nobreza, oficiais das ordenanças, letrados, médicos, escrivães e tabeliães, que iriam participar do poder municipal quando, a partir de 1782, a aldeia de Cuba foi elevada a vila65. Já em São Miguel, os dados recolhidos para o século XVIII, relativos à cidade de Ponta Delgada e às cinco vilas da ilha, confirmam que os dotes de património incidiam sobretudo em bens de raiz (terras de pão lavradias, vinhas, casas e lagares) e foros fixos; que os candidatos beneficiavam de dotações efectuadas por parentes (pais, tios, padrinhos) ou protectores, mas também podiam fazer dotes a si mesmos, caso possuíssem os bens necessários para o efeito; e que os dotadores eram elementos das nobrezas concelhias, oficiais das ordenanças (capitães e alferes), mercadores e lavradores ${ }^{66}$.

Em relação ao ingresso das jovens nos mosteiros, apesar dos dotes de religião serem menos onerosos do que os dotes de casamento, o seu valor, ao qual se acrescentavam as despesas com a cerimónia da profissão, o enxoval, as ofertas e o mobiliário para a cela ${ }^{67}$, implicava uma selecção e contribuía para afastar da vida religiosa uma fatia da população, de menos posses, embora os padroeiros dos conventos não omitissem a inclusão, nos documentos fundadores, de cláusulas que reservavam certos lugares para parentes pobres. Outros, no entanto, como no caso do mosteiro de São João, em Ponta Delgada, estipulavam a exclusão de filhas de mecânicos, apenas podendo entrar "pessoas nobres e honradas e que o patrimonio não seja menos de tres moios de propriedade", sendo as excepçōes reguladas pelo bispo ou pelo padroeiro ${ }^{68}$.

64 Fernando de SOUSA, "O Clero da diocese do Porto...", opus cit.

65 Emília Salvado BORGES, Homens, Fazenda e Poder..., opus cit., pp. 127-129 e 144-145.

66 José Damiāo RODRIGUES, São Miguel no século XVIII..., opus cit., vol. I, pp. 481-489.

67 Pedro de BRITO, Patriciado urbano quinhentista..., opus cit., pp. 295-296; José Damião RODRIGUES, São Miguel no século XVIII..., opus cit., vol. I, p. 488.

68 José Damião RODRIGUES, São Miguel no século XVIII..., opus cit., vol. I, p. 481. 
$\mathrm{Na}$ ausência dos progenitores ou quando estes, por qualquer motivo, não tinham condições para assegurar o pagamento do dote, o recurso aos parentes era comum, fossem eles membros da família exteriores ao convento ou até religiosas professas. Se, por vezes, era efectuado um empréstimo de dinheiro, noutras ocasiōes a solidariedade familiar manifestava-se através do pagamento integral do dote, sem que fossem impostas quaisquer condiçôes. Para se ter uma ideia do valor dos dotes de religião e das suas implicações económicas, mesmo para a sobrevivência dos próprios mosteiros, apresentamos em seguida três exemplos.

Em Lamego, no mosteiro das Chagas, da ordem de Santa Clara, o bispo D. Nuno Álvares Pereira de Melo, em visitação realizada no ano de 1715, fixou o valor dos dotes em 2.000 cruzados cada, "por rezão da grande carestia dos annos". Mas a necessidade de um dote tão elevado prendia-se também com o número de "criadas de dentro" existentes (catorze, em 1715), o que acarretava uma excessiva despesa ${ }^{69}$. No Real Mosteiro de Nossa Senhora da Conceição, em Beja, no final do século XVII, o montante dos dotes das candidatas a freiras era de 400.000 réis para as cristãs-velhas e de 600.000 para as cristãs-novas, a que se somavam 100.000 réis para a tença e gastos de entrada. Em 1717, entraram para o mosteiro nove jovens, todas ligadas por laços de sangue e oriundas do Brasil. Conhecidas como o grupo das baianas ou as brasileiras, fizeram entrar no mosteiro a elevada quantia de 8.000 .000 réis de dotes, o que lhes permitiu, nos anos seguintes, deter uma posição de relevo na vida da instituição ${ }^{70}$. Nos Açores, até 1705 , os dotes de religião eram, em geral, no valor de 310.000 réis (300.000 réis de dote e 10.000 réis de jóia de sacristia) ou 320.000 réis (neste caso, adicionando-se uma esmola de 10.000 réis); de 1705 em diante, passaram a ser de 420.000 réis (400.000 réis de dote e 20.000 réis de jóia de sacristia). Esta alteração veio perturbar as estratégias familiares, ao interferir com os rendimentos das casas e a sua aplicação. Em 1714, no contexto de uma avaliação dos bens dos eclesiásticos, os tabeliães foram proibidos de fazer escrituras de dotes de religião que não contemplassem uma côngrua vitalícia de apenas 25 ou 30.000 réis; mas, finalmente, em resposta às súplicas dos Franciscanos, D. João $\mathrm{V}$ fixou o montante dos dotes em 420.000 réis pela carta de 28 de Setembro de 1716. Na sequência desta imposição, desenhou-se um cenário no interior dos mosteiros caracterizado, durante algumas décadas, pela convivência de religiosas que haviam professado com 310.000 réis e de outras que o haviam feito com 420.000 réis. Esta situa-

69 BNL, Fundo Geral, cod. 8963, Lamego Visitações do Convento das Chagas, fls. 40$-47 \mathrm{v}$, maxime fls. $45 \mathrm{v}$ e 47.

70 Alfredo SARAMAGO, Convento de Soror Mariana Alcoforado. Real Mosteiro de Nossa Senhora da Conceição. Ensaio histórico, Sintra, 1994, pp. 101-104. 
ção criou uma divisão nas comunidades de freiras, tendo também dado origem a comportamentos discriminatórios por parte das madres superioras relativamente às professas mais recentes ${ }^{71}$.

Apesar do valor dos dotes, a entrada de jovens para as casas monásticas não se viu interrompida até à segunda metade de Setecentos e o número total de religiosas e de pessoal auxiliar (aias, criadas) que vivia intra-muros excedia, em grande parte dos casos, os limites fixados por ocasião da fundação. A presença de um elevado contingente de supranumerárias era regularmente denunciada, nomeadamente em visitas ad limina ${ }^{72}$, mas dificilmente podia ser evitada: a pressão demográfica existente no seio de muitas famílias nobres ou dos estratos superiores do terceiro estado, as estratégias familiares relacionadas com as alianças matrimoniais e os dotes de casamento e as despesas que os mosteiros tinham de enfrentar contribuíam, de forma conjugada, para alimentar a admissão de noviças e professas.

A entrada contínua dos filhos e filhas da nobreza e das camadas superiores do estado popular para os quadros da Igreja, se proporcionava prestígio, mais nuns casos do que noutros, e solucionava problemas relacionados com as políticas matrimoniais e a transmissão de bens ${ }^{73}$, colocava as famílias perante a urgência de encontrarem respostas para a questão dos dotes, garantindo que os bens dotais não seriam definitivamente perdidos. Isto era particularmente importante para as famílias cuja posição social e riqueza eram mais frágeis, como as que compunham os escalóes inferiores da clientela brigantina. Para este grupo, onde se registava uma taxa de celibato definitivo masculino superior a $80 \%$ e os dotes para tomar ordens sacras eram mais baixos, entre 120.000 e 200.000 réis, a circulação dos dotes sacerdotais dentro do círculo da parentela foi uma soluçãa $^{74}$. Esta foi igualmente a opção de sacerdotes que pertenciam a famílias das nobrezas locais ou, pelo menos, que eram afazendadas. A nomeação de irmãos clérigos ou, sobretudo, de sobrinhos como herdeiros significava a permanência do património no interior do círculo de parentes e a continuidade de uma presença familiar na Igreja. Ao lado dos clérigos, homens e mulheres, recorrendo às suas terças, instituíram vínculos para sobrinhos, filhos segundos, com a obrigação destes serem clérigos,

71 José Damião RODRIGUES, São Miguel no século XVIII..., opus cit., vol. I, pp. 482-485.

72 Carlos de AZEVEDO, "A cidade do Porto nos relatórios das visitas «ad limina» do Arquivo do Vaticano", Revista de História, vol. II, Actas do Colóquio "O Porto na Época Moderna", 1979, pp. 175-204.

73 Maria Ivone da Paz SOARES, Sociabilidade Feminina..., opus cit., pp. 322-326.

74 Mafalda Soares da CUNHA, A Casa de Bragança..., opus cit., pp. 500-501 e 506-508 . 
ou fundaram morgadios regulares, com cláusulas para os sucessores na administração poderem fazer património para clérigos, regressando os bens dotados à posse do administrador por óbito dos beneficiados.

Tomando como referência os elementos apurados para a ilha de São Miguel, refiramos que, apesar de um certo número de instituições determinar que a administração pertenceria sempre a homens da Igreja, o facto de estes não poderem ter filhos, devido aos seus votos, e, por esse motivo, de nomearem irmãos ou sobrinhos como herdeiros dos bens constituía um factor de deriva do património de uma dada linha para outra, por vezes mais afastada do tronco central familiar. Acrescentemos ainda que, na ausência de parentes próximos ou de uma forte "consciência de linhagem", os clérigos podiam eleger a sua alma como herdeira ou, então, uma confraria, o que representaria para a família a perda dos bens. Deste modo, as reservas que encontramos em algumas instituiçôes de vínculos no respeitante à sucessão de clérigos na administração dos mesmos parecem radicar no receio de alienação das bases materiais das casas ou das suas linhas principais. Quanto às freiras, existiam legados familiares que lhes eram destinados, geralmente por parte de tios, mas implicando a exclusão dos morgadios ${ }^{75}$, cuidado sempre presente por forma a impedir que os mosteiros, após a morte das professas, se apropriassem dos bens. Não podendo declarar abertamente esse temor, os instituidores excluíam as religiosas da sucessão, alegando que "como profeçam pobreza não hé bem que posuam digo que admenestrem bens profanos" 76 .

Com um crescimento contínuo desde cerca de 1500 até meados do século XVIII, a partir do terceiro quartel de Setecentos assistiu-se a uma redução, por vezes muito acentuada, no número de ingressos nas ordens e congregaçōes religiosas. Em termos sociais, esta evolução detecta-se tanto quando contemplamos as estratégias reprodutivas das casas dos Grandes como as das famílias das nobrezas locais e vários estudos, para instituiçóes distintas no reino e nas ilhas (Madeira, Açores), denunciam esta tendência. A contribuição mais recente de Susana Goulart Costa, tendo como base a ilha de São Miguel, confirma a viragem nos modelos e nas práticas da religião nos anos de 1770-1780. A autora situa-nos perante a secundarização da componente religiosa no discurso testamentário e a emergência do testamento como um "mero instrumento legal", processo que, de resto, caminha a par da diminuição no número de visitações ${ }^{77}$.

As causas são complexas e precisamos de aprofundar o nosso conhecimento neste campo, mas, desde já, podemos sugerir como possíveis fac-

75 Pedro de BRITO, Patriciado urbano quinhentista..., opus cit., p. 296.

76 José Damião RODRIGUES, São Miguel no séc. XVIII..., opus cit., vol. II, pp. 746$-747$.

77 Susana Goulart COSTA, Viver e morrer..., opus cit., pp. 78-80 (visitações) e 478-485. 
tores explicativos, mais até do que a influência da "cultura das Luzes" e a laicização dos valores, o impacto da legislação pombalina, mormente as leis de 1766, 1769 e 1770, e a transformação dos modelos reprodutivos nobiliárquicos, com o início de um processo de "desqualificação das carreiras eclesiásticas no mundo das elites"78. De qualquer modo, face à diversidade de situaçóes que caracterizava o universo das ordens religiosas e as várias casas no Antigo Regime, somente a continuação dos estudos permitirá confirmar a amplitude desta tendência evolutiva e determinar quais foram as suas consequências nos respectivos contextos geográficos e sociais.

\subsection{Comportamentos e vida familiar.}

Os problemas elencados até ao momento aumentam quando pretendemos aceder ao quotidiano dos homens e mulheres que compunham o corpo clerical, apreender os seus comportamentos e, até, surpreender a sua vida familiar, legítima ou não, face aos votos de castidade. Neste particular, a consulta dos livros de visitas, para o universo paroquial ou o mundo conventual, revela-se fundamental e muita informação foi já coligida $^{79}$. Todavia, é preciso aprofundar a recolha documental e esclarecer aparentes contradições. Por exemplo, em relação a "comportamentos morais e condutas religiosas indevidas" do clero, José Pedro Paiva escreveu que a impressão geral que se tem é de que seriam os clérigos desempregados os grandes responsáveis por essas falhas ${ }^{80}$. Ora, na diocese do Porto, no final do Antigo Regime, muitos sacerdotes que viviam amancebados e tinham filhos eram clérigos colados, entre os quais vigários, mesmo em agregados urbanos importantes à escala local, como Vila Real:

78 José Pedro PAIVA, “Os mentores”, opus cit., pp. 202-203; Fernanda OLIVAL, Nuno Gonçalo MONTEIRO, “Mobilidade social nas carreiras...”, opus cit., p. 1236.

79 Carlos de AZEVEDO, "A cidade do Porto nos relatórios....", opus cit.; Joaquim Ramos de CARVALHO, José Pedro PAIVA, "A evolução das visitas pastorais na diocese de Coimbra nos séculos XVII e XVIII", Ler História, no 15, 1989, pp. 29-41; Susana Goulart COSTA, "Visitas pastorais na Paróquia do Faial da Terra: apontamentos para o estudo das religiosidades de Antigo Regime (1698-1765)", Arquipélago-história, 2a série, vol. III, 1999, pp. 65-118; Artur Teodoro de MATOS, "Vivências, comportamentos e percursos...", opus cit.; José Pedro PAIVA, "A administração diocesana...", opus cit.; Maria Ivone da Paz SOARES, Sociabilidade Feminina..., opus cit.; Fernando de SOUSA, "Subsídios para a História Social...”, opus cit.; As Visitas Pastorais da Matriz de São Sebastião de Ponta Delgada (1674-1739), transcrição e notas de Maria Fernanda Dinis ENES, Angra do Heroísmo-Ponta Delgada, 1986.

80 José Pedro PAIVA, "Os mentores”, opus cit., p. 225; José Pedro PAIVA, “The Portuguese Secular Clergy...”, opus cit., p. 165. 
era o caso do vigário de São Pedro de Bragado, com 34 anos, que "fóra da igreja, éra lobo, na propria freguezia" 81 . Os comportamentos espelhados nas fontes da época, dos textos de Gil Vicente às visitas, não dizem unicamente respeito às práticas sexuais, mas também à falta de empenhamento no exercício do múnus sacerdotal, pecha que afectava um leque amplo de indivíduos, como o vigário de São Pedro de Vila Real, padre Francisco Ribeiro de Carvalho Pimentel, de 50 anos, formado em Leis, mas que confessava mal, pelo que o visitador o considerou "verdadeiramente barca de passagem" 82 . Outros, ainda, praguejavam, lutavam ou vendiam géneros em suas casas e regateavam a compra de carne e peixe ${ }^{83}$.

Mas, para além destas informações, que nos dizem algo acerca da vivência quotidiana, da formação e da vida familiar e afectiva destes homens, muito fica por esclarecer. Quantos viviam sós ou com parentes e criados? E faziam-no em casa própria ou de familiares (pais, irmãos, tios)? E quantos padres coabitavam, estivessem ou não ligados por laços de sangue? Aqui, o recurso aos róis de confessados é uma via a explorar ${ }^{84}$, cruzando os dados aí recolhidos com outras fontes, nomeadamente livros de notas de tabeliães, processos inquisitoriais, visitas e testamentos, de modo a apreendermos as trajectórias individuais dos clérigos e as relações intrafamiliares.

Dentro desta vertente de análise, importa focar a atenção nas tensões entre o colectivo e o individual, entre as estratégias familiares e as prováveis vocaçōes, aspecto que não desenvolvemos aqui, mas foi trabalhado por Maria de Lurdes Correia Fernandes na exploração que fez da "vida" do jesuíta João Cardim (1585-1615). A autora mostra que existia uma pressão por parte de parentes para que o jovem, filho varão, não seguisse a vida religiosa, e que este, embora adiando a sua entrada na Companhia - só o faria aos 26 anos -, não desistiu da sua determinação, influenciado pela leitura de livros espirituais, pelos "exercícios santos" do pai, o exemplo virtuoso da mãe e ainda o modelo dos tios, missionários jesuítas ${ }^{85}$.

81 Fernando de SOUSA, “Subsídios para a História Social...”, opus cit., p. 472.

82 Fernando de SOUSA, "Subsídios para a História Social...”, opus cit., p. 567.

83 José Damiāo RODRIGUES, “A Estrutura Social”, opus cit., p. 417.

84 José Damião RODRIGUES, Artur Boavida MADEIRA, "População e família em Ponta Delgada na segunda metade de Setecentos: a freguesia de São Pedro", População e Sociedade - Revista do Centro de Estudos da População e Família, no 2, 1996, pp. 207-228; José Damião RODRIGUES, Artur Boavida MADEIRA, Paulo Lopes MATOS, "População e família de uma vila açoriana: as Velas da ilha de São Jorge (1766-1799)", População e Sociedade - Revista do Centro de Estudos da População e Família, no 4, 1998, pp. 59-93; José Damião RODRIGUES, São Miguel no séc. XVIII..., opus cit., vol. II, pp. 577-598.

85 Maria de Lurdes Correia FERNANDES, "Entre a família e a religião: a «Vida» de João Cardim (1585-1615)", Lusitania Sacra, 2a série, vol. V, Jesuitas na Cultura e 
Este interessante estudo revela-nos a importância do círculo familiar e dos modelos, mormente os de santidade, na tomada de decisões, embora, no caso presente, aos modelos paternos se opusesse uma lógica familiar de aliança. A mesma autora, em texto posterior ${ }^{86}$, destacou o papel dos directores espirituais no contexto de uma valorização da educação cristã, moral e social, dos filhos e a influência de algumas figuras, como o carmelita frei Estevão da Purificação (1571-1617).

Mas atrevemo-nos também a referir o eventual papel das relações de amizade e de companheirismo quer na escolha de uma vida ao serviço de Deus, quer na definição de possíveis trajectórias. Este é um tópico difícil de delimitar, mas que deve ser entendido no contexto da Contra-Reforma, que recuperou o modelo hagiográfico, visando apresentar aos devotos exemplos de um comportamento a seguir. Os textos cronísticos de finais do século XVI e da centúria seguinte contêm elementos passíveis de serem explorados no que toca a esta questão. A título de exemplo, refiramos o caso de Diogo de Bairos, natural de Faro, e Manuel Fernandes, natural de Elvas, "ambos grandes amigos", que, sendo estudantes, na sequência do desastre de Alcácer Quibir, "imputando a isto a seus grandes pecados", escolheram a Ordem Seráfica como via da salvação ${ }^{87}$. Professaram, um tomando o nome de Diogo da Madre de Deus, o outro de Manuel da Anunciação. Em Lisboa, suspiravam por um recanto ermo e sossegado. Após ter-lhes sido indicado o retiro de Nossa Senhora de Mil Fontes, no Algarve, acabariam por viajar para a ilha de São Miguel, em 1614, fundando uma congregação de eremitas na ermida de Nossa Senhora da Consolação, situada nas Furnas, local ermo e marcado por fenómenos de vulcanismo, o que confere à escolha dos religiosos uma dimensão de entrega e de heroicidade, perfeitamente adequadas às propostas da espiritualidade católica pós-tridentina. Cremos que uma releitura das crónicas monásticas do período moderno poderá sugerir novas pistas quanto à importância exemplar de homens e mulheres "comuns" na formação de modelos e na génese de práticas devocionais, bem como na sua implantação regional ${ }^{88}$.

Sociedade Portuguesa, 1993, pp. 93-120.

86 Maria de Lurdes Correia FERNANDES, "Da reforma da Igreja...”, opus cit.

87 Agostinho de MONTALVERNE (Frei), Crónicas da Provincia de S. João Evangelista das Ilhas dos Açores, Ponta Delgada, vol. II, 1961, pp. 355-356.

88 Federico PALOMO, A Contra-Reforma em Portugal 1540-1700, Lisboa, 2006. 


\section{Perspectivas historiográficas.}

O rol de dúvidas e de problemas que fomos elencando traduz, conforme foi já reconhecido, o "relativo atraso da história religiosa e eclesiástica portuguesa" 89 . Em primeiro lugar, é necessário inventariar as fontes disponíveis, dispersas por inúmeros arquivos - mormente, os arquivos diocesanos e paroquiais -, e organizá-las de forma adequada, respeitando a lógica da sua produção e contemplando os princípios do respeito dos fundos e das séries e da territorialidade dos arquivos; seguidamente, verificar o "estado da arte", identificar as questôes em aberto e definir os programas e as metodologias de pesquisa que melhor poderão responder à urgência das investigações. Em nosso entender, a clarificação das linhas de força da interacção entre família e clero e a superação do actual nível de conhecimentos passam por uma aposta na microanálise como escala de observação preferida, com relevo para a identificação rigorosa de actores e respectivos grupos familiares e o rastreio dos itinerários individuais, explorando-se as relações interpessoais dos indivíduos, os desenhos e as dinâmicas das redes relacionais ${ }^{90}$ e os diversos espaços sociais nos quais se moviam. A partir da elaboração de micro-biografias ou de prosopografias poderemos, então, partir para a construção de uma tipologia das carreiras eclesiásticas e conseguir uma visão global mais correcta da Igreja e dos seus membros: clérigos, frades e freiras. Particular atenção deverá ser concedida à revisão de certos tópicos. A instituição de morgadios de segundogenitura registada para São Miguel, do mesmo modo que a inversão do modelo da primogenitura assinalada para as clientelas da casa de Bragança ${ }^{91}$, alertam-nos contra o perigo das ideias feitas. Por outro lado, o esforço, necessariamente colectivo ${ }^{92}$, para fazer progredir a história social em Portugal deverá inscrever com rigor os ciclos de vida, individuais e colectivos, nos quadros locais e regionais, territorializando a interpretação, e procurar perceber como é que as diferentes etapas e conjunturas da história nacional e eclesiástica condicionaram esses quadros e afectaram a existência dos actores e das instituições, em particular a família e a Igreja.

89 José Pedro PAIVA, “Os mentores”, opus cit., p. 201.

90 Pedro de BRITO, “- «Verflechtung» - Um Método para a Pesquisa, Exposição e Análise de Grupos Dominantes”, Penélope. Fazer e Desfazer a História, no 9/10, 1993, pp. 231-241.

91 Mafalda Soares da CUNHA, A Casa de Bragança..., opus cit., pp. 353-357.

92 Margarida Sobral NETO, "Sociedades Rurais de "Antigo Regime»" in José Jobson ARRUDA, Luís Adão da FONSECA (org.), Brasil-Portugal: História, agenda para o milênio, Bauru-São Paulo-Lisboa, 2001, pp. 343-354. 


\section{Bibliografia seleccionada}

AZEVEDO, Carlos Moreira (dir.), Dicionário de História Religiosa de Portugal, 4 vols, Lisboa, 2000-2001.

AZEVEDO, Carlos Moreira (dir.), História Religiosa de Portugal, Humanismos e Reformas, vol. 2, Lisboa, 2000.

BOONE III, James L., "Parental Investment and Elite Family Structure in Preindustrial States: A Case Study of Late Medieval-Early Modern Portuguese Genealogies", American Anthropologist, vol. 88, no 4, 1986, pp. 859-878.

COSTA, Susana Goulart, Viver e morrer religiosamente. Ilha de São Miguel, século XVIII, Ponta Delgada, 2007.

FARIA, Ana Mouta, "Função da carreira eclesiástica na organização do tecido social do Antigo Regime”, Ler História, Lisboa, no 11, 1987, pp. 29-46.

LALANDA, Maria Margarida de Sá Nogueira, A admissão aos mosteiros de Clarissas na ilha de S. Miguel (Sécs. XVI e XVII), dissertação de provas de A. P. C. C., Ponta Delgada, 1987, policopiado.

MONTEIRO, Nuno Gonçalo, O Crepúsculo dos Grandes. A casa e o património da aristocracia em Portugal (1750-1832), Lisboa, 1998.

OLIVAL, Fernanda e MONTEIRO, Nuno Gonçalo, "Mobilidade social nas carreiras eclesiásticas em Portugal", Análise Social, Lisboa, vol. XXXVII, no 165, Inverno 2003, pp. 1213-1239.

PAIVA, José Pedro, Os Bispos de Portugal e do Império 1495-1777, Coimbra, 2006.

RODRIGUES, José Damião, São Miguel no século XVIII: casa, elites e poder, Ponta Delgada, 2003 [2004], 2 vols. 